\title{
ROSTRAL-CAUDAL VARIATION IN TROPONIN T AND PARVALBUMIN CORRELATES WITH DIFFERENCES IN RELAXATION RATES OF COD AXIAL MUSCLE
}

\author{
TIERNEY M. THYS ${ }^{1, *}$, JASON M. BLANK ${ }^{2}$ AND FRED H. SCHACHAT ${ }^{2}$ \\ ${ }^{1}$ Department of Zoology, Duke University, Durham, NC 27708-0325, USA and 2 Department of Cell Biology, \\ Duke University, Durham, NC 27710, USA \\ *Present address: Sea Studios, 810 Cannery Row, Monterey, CA 93940, USA (e-mail: tierney@ seastudios.com)
}

Accepted 13 August; published on WWW 8 October 1998

\begin{abstract}
Summary
Relaxation rate is an important determinant of axial muscle power production during the oscillatory contractions of undulatory locomotion. Recently, significant differences have been reported in the relaxation rates of rostral versus caudal white muscle fibers of the Atlantic cod Gadus morhua L. The present study investigates the biochemical correlates of this rostral-caudal physiological variation. Using denaturing gel electrophoresis, a series of fresh muscle samples from the dorsal epaxial muscle region was analyzed and several differences were detected. First, a gradual shift occurs in the expression of two troponin $T$ isoforms along the length

of the body. Second, rostral muscles were found to contain significantly greater amounts of parvalbumin than caudal muscles. Third, two soluble $\mathrm{Ca}^{2+}$-binding proteins, in addition to parvalbumin, were also detected in the rostral muscle samples yet were absent from the caudal samples. This suite of rostral-caudal variations provides a strong biochemical basis for regional differences in the relaxation rates of cod white muscle.

Key words: axial muscle, relaxation, Atlantic cod, Gadus morhua, contractile protein, parvalbumin, troponin $\mathrm{T}$, regional variation.
\end{abstract}

\section{Introduction}

Relaxation rate has been hypothesized to be an important determinant of contractile frequency (Altringham and Johnston, 1990) and power generation in the axial muscles of fish (Moon et al. 1991; Rome and Swank, 1992; Rome et al. 1993; Johnson et al. 1994). After completing the shortening phase of its contraction cycle, a muscle must relax rapidly if it is to be extended with little resistance (Josephson, 1981). Hypothetically, maximum power can be achieved if muscle is 'turned on' instantaneously at the start of shortening and 'turned off' instantaneously just before lengthening (Marsh, 1990). A longer caudal relaxation rate can increase differences in the phase relationship between muscle strain and excitation. Differences in this phase relationship can have profound effects on the mechanical behavior of skeletal muscle (Josephson, 1985; Altringham and Johnston, 1990; Johnson and Johnston, 1991; Altringham et al. 1993). The resistance of active caudal muscles to being stretched (negative work) can act to stiffen the tail region, which can increase tail thrust. Thus, the rate at which caudal muscle relaxes can play a vital role, not only in the amount of negative work the muscle performs but also in determining the overall thrust produced by the tail region, which ultimately affects the performance of the whole organism (Swank et al. 1997).

Recent work by Davies et al. (1995), comparing rostral versus caudal mechanical properties of Atlantic cod Gadus morhua L. axial muscle fibers, documents a significant rostral-caudal difference in relaxation rates: the time required to relax to half peak isometric tension averaged $54.0 \pm 2.9 \mathrm{~ms}$ (mean \pm S.E.M.) for rostral single fibers and $88.3 \pm 8.0 \mathrm{~ms}$ for caudal fibers. Similar differences have been reported for the white muscle fibers of pollack Pollachius virens (Altringham et al. 1993) and the red muscle fibers of scup Stenotomus chrysops (Rome et al. 1993). The present study explores the biochemical basis of rostral-caudal variation in cod axial muscle relaxation rate.

Relaxation of skeletal muscle after a single twitch or tetanic contraction is initiated by a reduction in myoplasmic $\mathrm{Ca}^{2+}$ concentration. Four major mechanisms are implicated in controlling relaxation. The first mechanism involves dissociation of $\mathrm{Ca}^{2+}$ from troponin $\mathrm{C}$. Troponin $\mathrm{T}$ is believed to affect this rate of dissociation, as has been shown in frogs (Baylor et al. 1983; Gillis, 1985) and rabbits (Schachat et al. 1987). The second mechanism involves facilitated diffusion of $\mathrm{Ca}^{2+}$ from the myofibrils to regions near the sarcoplasmic reticulum. Parvalbumin, a low-molecular-mass $\mathrm{Ca}^{2+}$-binding protein, has been shown to play a key role in this process in both frogs (Hou et al. 1991) and mice (Müntener et al. 1995). A third mechanism involves uptake of $\mathrm{Ca}^{2+}$ into the sarcoplasmic reticulum by the $\mathrm{Ca}^{2+}$-ATPase pump (e.g. frog, Baylor et al. 1983; numerous vertebrates, Gillis, 1985; teleosts, 


\section{T. Thys, J. M. Blank And F. H. Schachat}

Rome et al. 1996; Swank et al. 1997). The number and/or efficiency of $\mathrm{Ca}^{2+}$-ATPase pumps determines the rate of $\mathrm{Ca}^{2+}$ uptake. A fourth mechanism involves changes in the actomyosin crossbridge detachment kinetics (rabbit, Greaser $e t$ al. 1988; Sweeney and Stull, 1990). Myosin isoforms can be a strong determinant of detachment kinetics.

The present study implicates the first two of these regulatory mechanisms in controlling rostral-caudal variation in the relaxation rate of cod axial muscle.

\section{Materials and methods Experimental animals}

Three specimens of fresh Atlantic cod Gadus morhua L. (cod GM01, $653 \mathrm{~mm}$; cod GM02, $635 \mathrm{~mm}$; cod GM03, $775 \mathrm{~mm}$ standard length) were obtained commercially from Maine waters during the months of May and June 1997 and March 1998. A fourth specimen (cod GM04, $470 \mathrm{~mm}$ standard length) was captured off the Massachusetts coast, maintained in captivity for several days at Northeastern University's Marine Science Laboratory in Nahant, MA, USA, and killed by pithing prior to axial muscle dissection.

\section{Myofibril preparation}

Fresh white muscle samples $(0.5-1.0 \mathrm{~g})$ were dissected from the epaxial arm and cone region of every sixth myomere and from one rostral and one caudal hypaxial cone site from cod GM01 (Fig. 1). Each muscle sample was minced on a chilled glass plate, transferred to an Eppendorf tube and suspended in $1 \mathrm{ml}$ of buffer A, containing $15 \mathrm{mmol}^{-1}$ Tris, pH 7.6, $100 \mathrm{mmoll}^{-1} \mathrm{NaCl}, 4 \mathrm{mmoll}^{-1}$ EGTA, $2 \mathrm{mmoll}^{-1}$ $\mathrm{MgCl}_{2}, \quad 7 \mathrm{mmol}^{-1} \quad \beta$-mercaptoethanol, $\quad 0.1 \mathrm{mmoll}^{-1}$ phenylmethylsulfonylfluoride (PMSF) and $75 \mathrm{ng} \mathrm{ml}^{-1}$ each of antipain, leupeptin and pepstatin A. Samples were vortexed

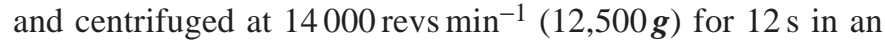
Eppendorf 5415 microcentrifuge, and the resulting pellet was resuspended in $1 \mathrm{ml}$ of buffer B (composition as for buffer A but containing only $0.3 \mu \mathrm{ml}^{-1}$ leupeptin, antipain and pepstatin). The samples were vortexed and centrifuged (at $12,500 \mathrm{~g}$ ), and the resulting pellets were incubated in $1 \mathrm{ml}$ of buffer C (buffer B plus $2 \%$ Triton X-100) for $10 \mathrm{~min}$. After recentrifugation at $(12,500 \mathrm{~g})$, the pellets were washed twice more with buffer B and resuspended in 1 vol of buffer B.

To prepare myofibrillar homogenates, fresh superficial white muscle samples were dissected from the epaxial arm region of every sixth myomere from cod GM02 and GM03. All samples were minced as described above and suspended in approximately 5 vols of buffer A supplemented with $0.6 \mathrm{~mol}^{-1}$ $\mathrm{NaI}$. Samples were incubated on ice for $10 \mathrm{~min}$ and centrifuged at room temperature $\left(21^{\circ} \mathrm{C}\right)$ for $2 \mathrm{~min}$ at $12,500 \mathrm{~g}$, and the supernatants were reserved for further characterization.

\section{$S D S-P A G E$}

\section{Sample preparation}

Gel samples were prepared by $1: 1$ dilutions with $2 \times$ Laemmli reducing buffer (2\% SDS, $50 \mathrm{mmoll}^{-1}$ Tris, pH 6.8, $20 \%$ glycerol, $1 \% \beta$-mercaptoethanol, Bromophenol Blue). Samples were then heated for $3 \mathrm{~min}$ at $100^{\circ} \mathrm{C}$, frozen until solid, reheated for $2 \mathrm{~min}$ at $100^{\circ} \mathrm{C}$, and centrifuged. Supernatants were diluted as necessary in Laemmli reducing buffer (Laemmli, 1970).

\section{Preparation of gels}

SDS-PAGE was performed according to Laemmli (1970) using $10.5 \%, 12.5 \%$ and $15 \%$ polyacrylamide-SDS gels as indicated. Mini-gels were run at room temperature on a BioRad Protean II cell, and full-sized gels were electrophoresed at $8{ }^{\circ} \mathrm{C}$ using Hoefer Scientific Instruments SE500 apparatus. Unless otherwise specified, all gels were fixed and stained with Coomassie Brilliant Blue G250 as described by Neuhoff et al. (1988).

Gels were scanned into Adobe Photoshop v. 3.05 with an Agfa Arcus II Scanner and quantification was performed with NIH Image v. 1.61. When necessary, intensity plots were fitted

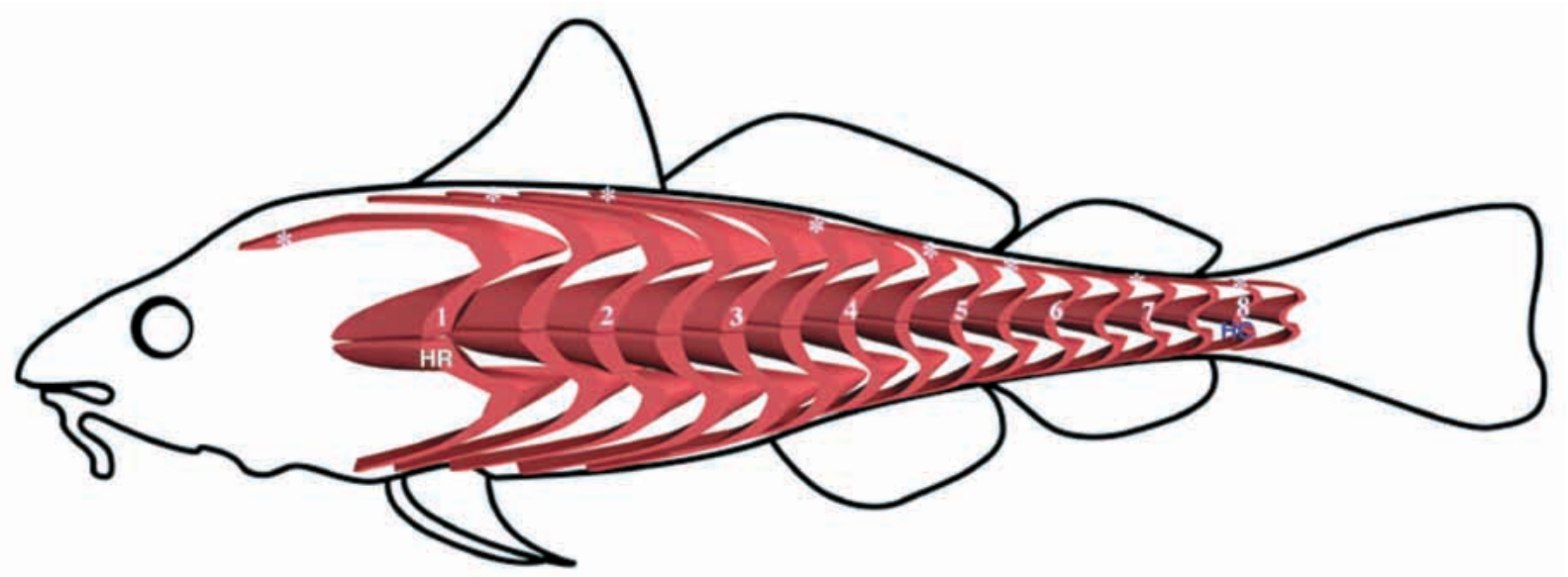

Fig. 1. Schematic drawing of cod axial muscle indicating sampling sites. Isolated white muscle myomeres are depicted in pink. Every sixth myomere is numbered. Arm sample sites are depicted by asterisks, and cone sample sites are depicted by numbers. Hypaxial cone samples are labeled: HR, hypaxial rostral cone site; HC, hypaxial caudal cone site. The drawing was constructed using Strata Studio Pro v. 1.75 with the help of Mark Johnston. 


\section{Contractile proteins in cod axial muscle 2995}

using Jandel PeakFit v. 4. The scanner was calibrated with a Kodak density step tablet (CAT 1523406), and dilutions of myofibril samples were run to ensure linearity of staining.

Relative molecular mass $\left(M_{\mathrm{r}}\right)$ was determined by comparing the relative mobility of the cod myofibrillar proteins with that of proteins from rabbit psoas myofibrils, whose molecular masses are known from direct sequencing or cDNA analysis.

\section{Immunoblotting (western blotting)}

Gel samples were prepared from homogenates, myofibrils or supernatants as indicated. Based on the method of Davies et al. (1995), four sample sites were selected; one epaxial rostral site, one epaxial caudal site, one hypaxial rostral site and one hypaxial caudal site from the right side of two individuals (cod GM02 and GM03). To normalize to levels of actin, two lanes were run for each sample: one for Coomassie staining, and the second for immunoblotting.

Parvalbumin was identified following transfer to nitrocellulose using monoclonal anti-parvalbumin mouse ascites fluid PA-235 (Sigma 3171) and the protocol outlined in the Vectastain ABC kit. The blot intensities were quantified densitometrically and normalized to actin using NIH Image.

\section{Ca ${ }^{2+}$-binding proteins}

Two-dimensional electrophoresis was performed using standard $12.5 \%$ SDS-PAGE with all solutions supplemented with $1 \mathrm{mmol}^{-1}$ EDTA in the first dimension and with $12.5 \%$ SDS-PAGE with all solutions supplemented with $1 \mathrm{mmoll}^{-1}$ $\mathrm{CaCl}_{2}$ in the second dimension. Lanes from the first dimension were excised and mounted horizontally on the stacker for the second dimension using an agarose solution containing 0.125 mol $^{-1}$ Tris, pH 6.8, $1.25 \%$ low-melting-point agarose (FMC Corp.), $0.1 \%$ SDS, 1:4000 $\beta$-mercaptoethanol and $1 \mathrm{mmol} \mathrm{l}^{-1} \mathrm{CaCl}_{2}$.

The gel was stained with Coomassie Brilliant Blue as described above. A right shift of the proteins away from the diagonal is an indicator of $\mathrm{Ca}^{2+}$ binding. $\mathrm{Ca}^{2+}$ binding to proteins displaces SDS, reducing the charge and mobility of $\mathrm{Ca}^{2+}$-binding proteins in the second dimension and resulting in an upward shift in position in the second dimension (Burgess et al. 1980).

\section{Protein purifications: myosin and troponin}

Owing to the inherent thermal instability of gadoid myosins (Connell, 1960; Castell et al. 1973; Laird and Mackie, 1981), special precautions were taken to ensure successful purification of the myosin and troponin myofibrillar subfractions. Axial muscle tissue samples were dissected from cod GM04, immediately frozen in liquid nitrogen and stored at $-80^{\circ} \mathrm{C}$ for 2 days.

Approximately $2 \mathrm{~g}$ of muscle from the arm region of site 3 (see Fig. 1) were pulverized in liquid nitrogen. The resulting powder was washed in 10 vols of chilled solution 1 $\left[50 \mathrm{mmol}^{-1}\right.$ Tris/ $\mathrm{HCl}, 30 \mathrm{mmoll}^{-1}$ Tris base, $50 \mathrm{mmoll}^{-1}$ $\mathrm{LiCl}, 15 \%$ glycerol (BRL Molecular Biology Grade), $7 \mathrm{mmol}^{-1} \beta$-mercaptoethanol, $0.1 \mathrm{mmoll}^{-1} \mathrm{PMSF}, 1 / 10000$
(25 mg ml-1) leupeptin] and centrifuged for $5 \mathrm{~min}$ at $3000 \mathrm{~g}$ in a Jouan CR412 refrigerated centrifuge. $\mathrm{LiCl}$ was incorporated into solution 1 since it has been shown to be more effective at extracting protein from fish muscle than either sodium chloride or potassium chloride under most conditions (Kelleher and Hultin, 1991). Glycerol was added to further stabilize against denaturation (Gekko and Timasheff, 1981). The supernatant from the first centrifugation was saved for the analysis of soluble proteins, and the pellet was washed a second time in 10 vols of solution 1. Myosin, troponin and tropomyosin were prepared by incubating the pellet in 3 vols of chilled extraction buffer $\left(1 \mathrm{~mol}^{-1} \mathrm{LiCl}, 25 \mathrm{mmoll}^{-1}\right.$ Tris/ $\mathrm{HCl}, 7.5 \mathrm{mmol}^{-1}$ Tris base, $\quad 15 \% \quad$ glycerol, $\quad 7 \mathrm{mmoll}^{-1} \quad \beta$-mercaptoethanol, $0.1 \mathrm{mmol}^{-1} \mathrm{PMSF}$ ) for $10 \mathrm{~min}$ at $0^{\circ} \mathrm{C}$. Following incubation, the sample was centrifuged for $75 \mathrm{~min}$ at $250,000 \mathrm{~g}$ at $2{ }^{\circ} \mathrm{C}$ in a 100Ti rotor in a Beckman tabletop ultracentrifuge. The supernatant, containing solubilized myofibrillar proteins, was dialyzed overnight at $4{ }^{\circ} \mathrm{C}$ against a low-salt solution $(15 \%$ glycerol, $25 \mathrm{mmol}^{-1} \mathrm{LiCl}, 30 \mathrm{mmol}^{-1}$ Tris/ $\mathrm{HCl}, 10 \mathrm{mmol} \mathrm{l}^{-1}$ Tris base, $2 \mathrm{mmol} \mathrm{l}^{-1} \mathrm{MgCl}_{2}, 1 \mathrm{mmol} \mathrm{l}^{-1}$ EGTA, $14 \mathrm{mmol}^{-1} \beta$ mercaptoethanol, $0.1 \mathrm{mmol}^{-1} \mathrm{PMSF}$ ) to precipitate the myosin. The dialysis solution was changed after the first $4 \mathrm{~h}$ and replaced with a fresh solution devoid of EGTA. Following dialysis, the sample was centrifuged at $4{ }^{\circ} \mathrm{C}$, and the pelleted myosin and the supernatant (containing mainly actin, tropomyosin and troponin) were separated. The supernatant was supplemented with $5 \mathrm{mmoll}^{-1}$ phosphate buffer and loaded onto a $5 \mathrm{ml}$ hydroxyapatite column. The column was washed with 2 vols of $5 \mathrm{mmol}^{-1}$ phosphate buffer $\left(5 \mathrm{mmol}^{-1}\right.$ phosphate, $0.6 \mathrm{moll}^{-1} \mathrm{LiCl}, 1 \mathrm{mmol}^{-1} \mathrm{MgCl}_{2}, 14 \mathrm{mmoll}^{-1} \beta$ mercaptoethanol, $0.1 \mathrm{mmol}^{-1} \mathrm{PMSF}, \mathrm{pH} 7$ ) and eluted with a linear $5 \mathrm{mmoll}^{-1}$ to $200 \mathrm{mmol}^{-1}$ phosphate gradient in the same salt at $4{ }^{\circ} \mathrm{C}$. Fractions $(1 \mathrm{ml})$ were collected and analyzed using SDS-PAGE.

\section{Results \\ Identification of the myosin, troponin and tropomyosin subunits}

The abundance of myofibrillar actin and myosin heavy chain makes them readily identifiable on denaturing polyacrylamide gels (Fig. 2). Unambiguous identification of the remaining myofibrillar proteins requires purified or enriched preparations. Myosin, troponin and tropomyosin were purified from the arm region of site 3 (Fig. 1), a site where all the major muscle proteins and their isoforms are expressed. Initial attempts at protein purification using standard techniques, however, resulted in aggregated and denatured proteins. Both formylation and thermal denaturation have been implicated in inducing aggregation of gadoid muscle proteins (Connell, 1960; Tokunaga, 1964; Castell et al. 1973; Laird and Mackie, 1981). To combat potential formylation, muscle samples were dissected immediately after the fish had been killed, flashfrozen in liquid nitrogen and stored at $-80^{\circ} \mathrm{C}$. The samples were then pulverized in liquid nitrogen and placed in a homogenization buffer supplemented with Tris, a primary 


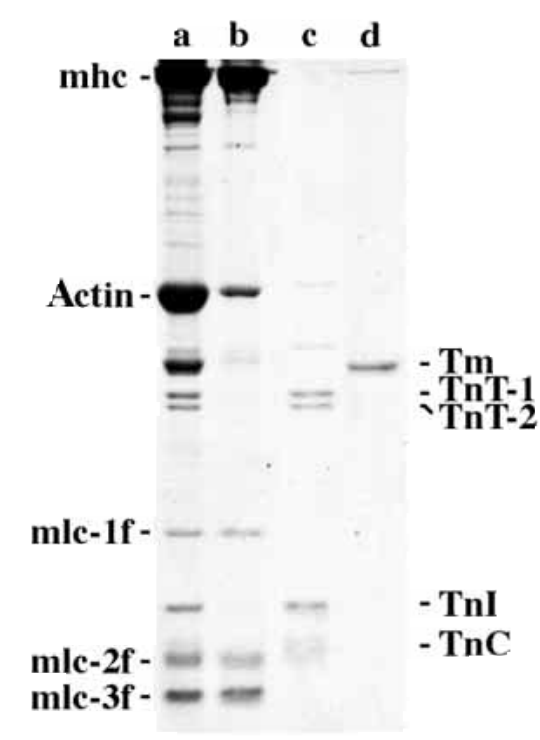

Fig. 2. Electrophoresis of purified cod contractile proteins. $12.5 \%$ SDS-PAGE was used to identify the subunits of cod axial muscle proteins. Myofibrils (lane a) were run for comparison with an enriched myosin preparation (lane b) and purified fractions of troponin (lane c) and tropomyosin (lane d). The three fast myosin light chains in the purified myosin sample are labeled mlc-1f, mlc-2f and mlc-3f, and the two fast troponin $\mathrm{T}$ species are labeled TnT-1 and TnT-2, where the numbers reflect the relative mobility of the proteins in ascending order. mhc, myosin heavy chain; TnI, troponin I; TnC, troponin C; Tm, tropomyosin.

amine that inhibits protein formylation by mass action. Further protein denaturation was prevented by (1) supplementing solutions with glycerol, (2) using the leiotrophic salt $\mathrm{LiCl}$ in place of $\mathrm{NaCl}$ or $\mathrm{KCl}$, and (3) performing all procedures at or below $0^{\circ} \mathrm{C}$, except for the hydroxyapatite chromatography which was performed at $4{ }^{\circ} \mathrm{C}$.

From the hydroxyapatite column chromatography fractions, the major myofibrillar protein subunits were readily identified using SDS-PAGE. Comparison of the homogenate with the myosin-enriched fraction (Fig. 2, lanes a and b, respectively) revealed the presence of three myosin light chain species designated mlc-1f, mlc- $2 \mathrm{f}$ and mlc-3f. The relative mobility of these light chains (compared with the mobility of rabbit fast myosin light chains) indicates that their relative molecular masses $\left(M_{\mathrm{r}}\right)$ are 21100,18670 and 18240 , respectively.

The purified troponin fraction (Fig. 2, lane c) revealed the presence of two TnT species (TnT-1 and TnT-2 ) with $M_{\mathrm{r}}$ values of 32110 and 30900 , respectively, a troponin I $\left(M_{\mathrm{r}}\right.$ 19040) and a troponin $\mathrm{C}\left(M_{\mathrm{r}}\right.$ 16940), which migrates just above mlc-2 $\mathrm{f}$ and is often difficult to resolve. Tropomyosin $\left(M_{\mathrm{r}}\right.$ 34580 ) is shown in Fig. 2, lane d.

\section{Arm versus cone}

SDS-PAGE of myofibrils from the arm and cone regions of the same myomere did not demonstrate significant differences in myofibrillar protein expression (Fig. 3), although a rostral-caudal transition in TnT isoforms was apparent. Because of the overall similarity between the arm and cone regions, subsequent investigations focused on rostral-caudal differences in the arm region alone. The less complicated morphology of the arm region also simplified the dissection of muscle samples from individual myomeres.

\section{Rostral versus caudal}

Investigation of both myofibrils (Fig. 3) and homogenates (Fig. 4) along the rostral-caudal axis by SDS-PAGE revealed a marked difference in the ratio of the TnT isoforms. The faster-migrating rostral TnT isoform, TnT-2, is gradually replaced by the slower-migrating caudal isoform, TnT-1. Fig. 5 quantifies the shift in TnT isoforms as a function of myomere position in the three cod sampled. Each animal exhibits a rostral to caudal shift from TnT-2 to TnT-1 expression; at the level of the third dorsal fin, site A6 (Fig. 1) (approximately two-thirds of the way down the body), all the TnT in both the arm and cone regions is composed of the slower-migrating TnT-1 isoform.

While the difference in TnT expression was the only
Fig. 3. Comparison of arm and cone myofibrillar proteins in cod myomeres. A $10.5 \%$ SDS gel stained with Coomassie Brilliant Blue G250, comparing samples from arm (A1-A8) and corresponding cone $(\mathrm{C} 1-\mathrm{C} 8)$ myofibrils from eight sequential myomeres of cod GM01 (standard length $653 \mathrm{~mm}$ ). Note that the arm and cone samples show similar muscle protein expression. Both regions show a rostral-caudal shift in two troponin $\mathrm{T}$ isoforms. A, arm; C, cone; Myo, myosin heavy chain; Tm, tropomyosin; TnT, troponin $\mathrm{T}$. Note that the faster-migrating rostral troponin $\mathrm{T}$, TnT-2, is gradually replaced by the slowermigrating caudal isoform TnT-1. At the level of the third dorsal fin (site A6, approximately two-thirds of the way down the body), all myofibrillar troponin $\mathrm{T}$ in both the arm and cone regions is of the slower-migrating TnT-1 isoform.

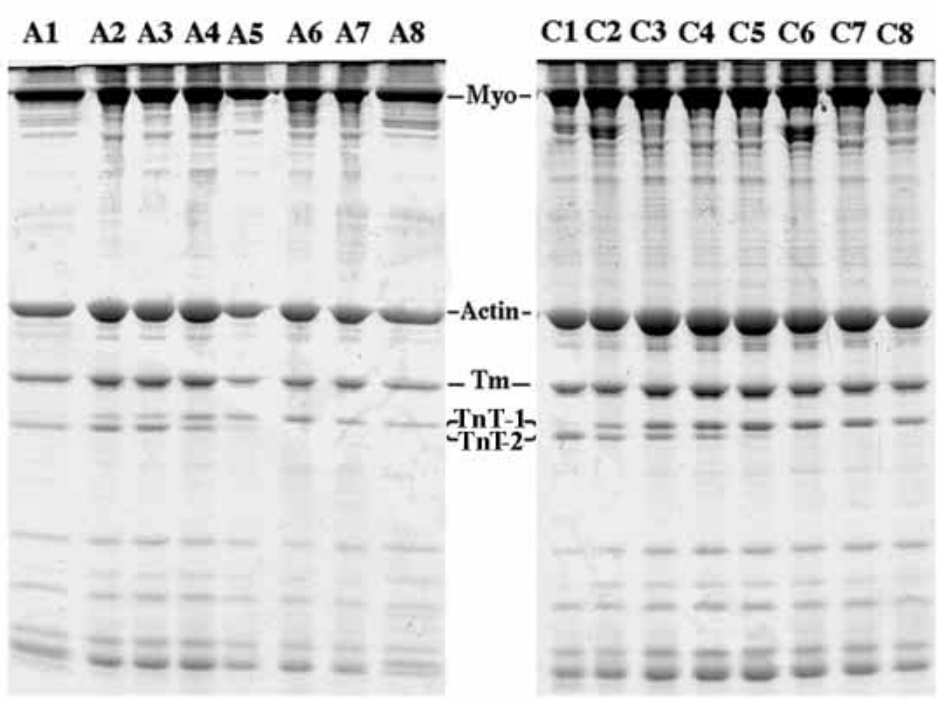


A

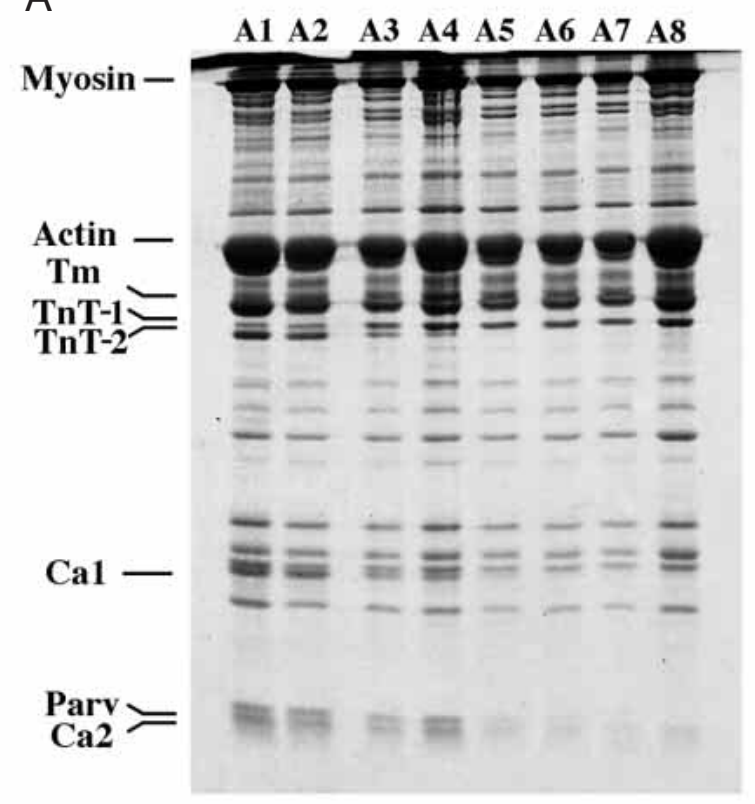

B

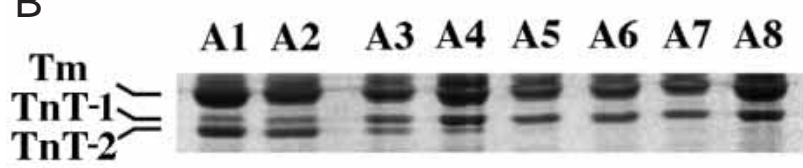

Fig. 4. Rostral-caudal variation in cod axial muscle homogenates. (A) A $12.5 \%$ SDS gel stained with Coomassie Brilliant Blue G250, comparing arm (A1-A8) myofibrillar homogenates from eight sequential myomeres of cod GM02 (standard length $635 \mathrm{~mm}$ ). (B) Magnification of the portion of the gel containing the troponin $\mathrm{T}$ isoforms. Four differences are detectable along the rostral-caudal axis: (1) a shift in the troponin isoforms from TnT-2 rostrally to TnT-1 caudally, (2/3) the presence of two $\mathrm{Ca}^{2+}$-binding proteins (Ca1 and $\mathrm{Ca} 2)$ in the rostral arm sites (A1-A4) and their absence from the caudal arm sites (A5-A8), and (4) larger amounts of parvalbumin (Parv) in the rostral arm sites (A1-A4) than in the caudal arm sites (A5-A8). Tm, tropomyosin.

myofibrillar variation, three additional rostral-caudal differences were characterized in the muscle homogenates (Fig. 4A). These differences appear to involve differential expression of low-molecular-mass cytosolic $\mathrm{Ca}^{2+}$-binding proteins in the rostral axial white muscle.

Of these three proteins, the protein with an intermediate $M_{\mathrm{r}}$ was identified as parvalbumin by western blotting. Greater amounts of parvalbumin $\left(M_{\mathrm{r}} 10320\right)$ are present rostrally than caudally, as demonstrated by western blotting (Fig. 6) and gels stained with Coomassie Brilliant Blue G250 (Fig. 4; Table 1). The relative abundance of parvalbumin was assessed by determining its concentration relative to that of actin. In cod GM03, the epaxial rostral site, A1, contains 8.3 times more parvalbumin than the caudal site A8. In cod GM02, a similar bias in rostral parvalbumin expression was observed. In the hypaxial muscle samples (HR and HC), both cod GM02 and GM03 show a similar elevation of rostral parvalbumin

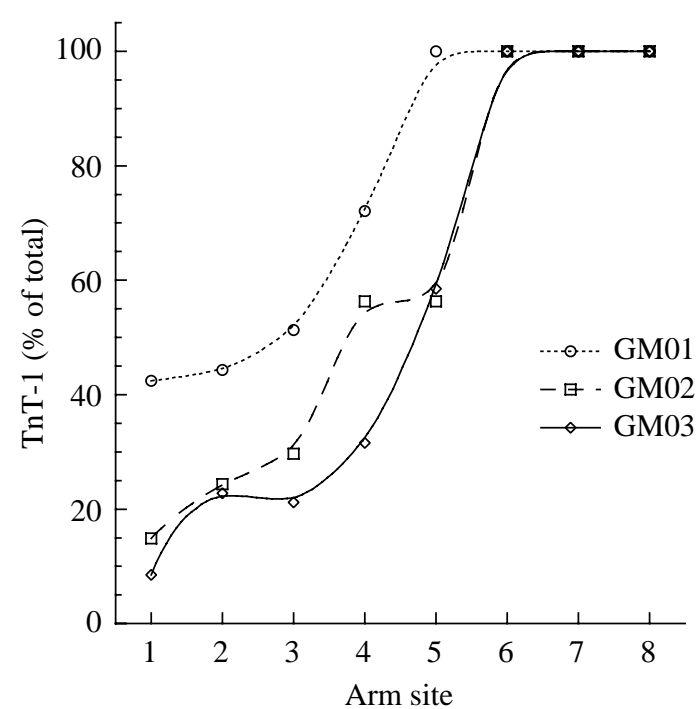

Fig. 5. Rostral-caudal variation in troponin $\mathrm{T}$ isoforms. The percentage of TnT-1 to total TnT (TnT1 plus TnT2) is plotted versus the axial sampling site (see Fig. 1) for the three cod in this study.

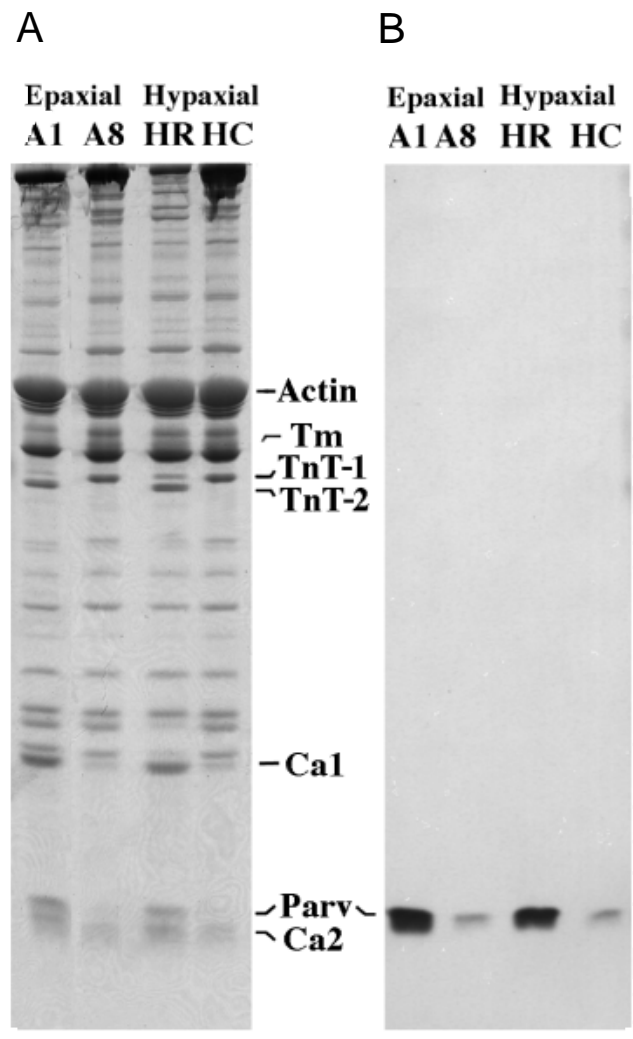

Fig. 6. Identification of parvalbumin by western blotting. (A) A $12.5 \%$ SDS-polyacrylamide gel of rostral arm (A1), rostral hypaxial (HR), caudal arm (A8) and caudal hypaxial (HC) myofibrillar homogenates stained with Coomassie Brilliant Blue G250. (B) Western blot of the same sample. Parvalbumin (Parv) is identified by reaction with a monoclonal antibody. Note that the rostral muscle sites A1 and HR contain significantly greater amounts of parvalbumin than do the caudal sites A8 and HC. Loads were balanced by actin content. Tm, tropomyosin; TnT-1, TnT-2, isoforms of troponin; $\mathrm{Ca} 1, \mathrm{Ca} 2, \mathrm{Ca}^{2+}$-binding proteins. 
Table 1. Parvalbumin content of rostral and caudal sites of cod axial muscle

\begin{tabular}{lcc}
\hline Sample site & $\begin{array}{c}\text { Fish GM02 } \\
\text { parvalbumin } \\
\text { content }\end{array}$ & $\begin{array}{c}\text { Fish GM03 } \\
\text { parvalbumin } \\
\text { content }\end{array}$ \\
\hline A1 & $0.143 \pm 0.001$ & $0.215 \pm 0.026$ \\
A8 & ND & $0.026 \pm 0.004$ \\
HR & $0.169 \pm 0.0003$ & $0.176 \pm 0.003$ \\
HC & ND & $0.003 \pm 0.001$
\end{tabular}

For details, see Fig. 1.

Values are means \pm S.D. $(N=3)$; ND, not detectable.

Levels of parvalbumin are normalized to levels of actin as determined densitometrically using NIH Image from gels stained with Coomassie Brilliant Blue G250.

Note that the rostral sites (A1, HR) have significantly greater amounts of parvalbumin than do caudal sites (A8, HC) ( $t$-test; $P<0.05)$.

expression with exceedingly low caudal parvalbumin levels (Table 1).

In addition to parvalbumin, two cytoplasmic proteins, designated $\mathrm{Ca} 1$ and $\mathrm{Ca} 2$ ( $M_{\mathrm{r}} 14800$ and 9900, respectively), are present in rostral samples (A1-A4) but are absent from caudal samples (A5-A8). Their identification as $\mathrm{Ca}^{2+}$-binding proteins is based on a mobility-shift assay. As shown in the two-dimensional gel in Fig. 7, proteins $\mathrm{Ca} 1$ and $\mathrm{Ca} 2$ shift to the right of the diagonal when electrophoresed in the presence of $1 \mathrm{mmoll}^{-1} \mathrm{Ca}^{2+}$. Such $\mathrm{Ca}^{2+}$-dependent mobility shifts are indicative of $\mathrm{Ca}^{2+}$ binding (Burgess et al. 1980). Like parvalbumin, both proteins are expressed at high levels in rostral sites and are undetectable in the most caudal sites (Fig. 4A).

In contrast to the systematic rostral-caudal variation in $\mathrm{TnT}$ and $\mathrm{Ca}^{2+}$-binding proteins, SDS-PAGE revealed no rostral-caudal differences in the expression of tropomyosin or alkali myosin light chains (Fig. 3A). The ratio of myosin light chains is virtually invariant rostrocaudally. Low-percentage polyacrylamide gel electrophoresis also failed to detect differences in the rostrocaudal distribution of the myosin heavy chain (data not presented). Given the observations of Davies et al. (1995), who report rostral-caudal differences in maximal contraction velocity, it is likely that higher-resolution techniques (e.g. cDNA sequencing) will reveal rostral-caudal variation in myosin heavy chain expression.

\section{Discussion}

The results of this study implicate several cod axial muscle proteins in the regulation of relaxation rates along the length of the body. Changes in the proportions of these proteins are likely to alter the dynamics of $\mathrm{Ca}^{2+}$ dissociation from the thin filament and affect the rate at which $\mathrm{Ca}^{2+}$ is removed from the myoplasm. The differences detected include (1) a rostral-caudal shift in isoform expression of troponin $\mathrm{T}$, a subunit of the thin filament $\mathrm{Ca}^{2+}$ regulatory complex, (2) a

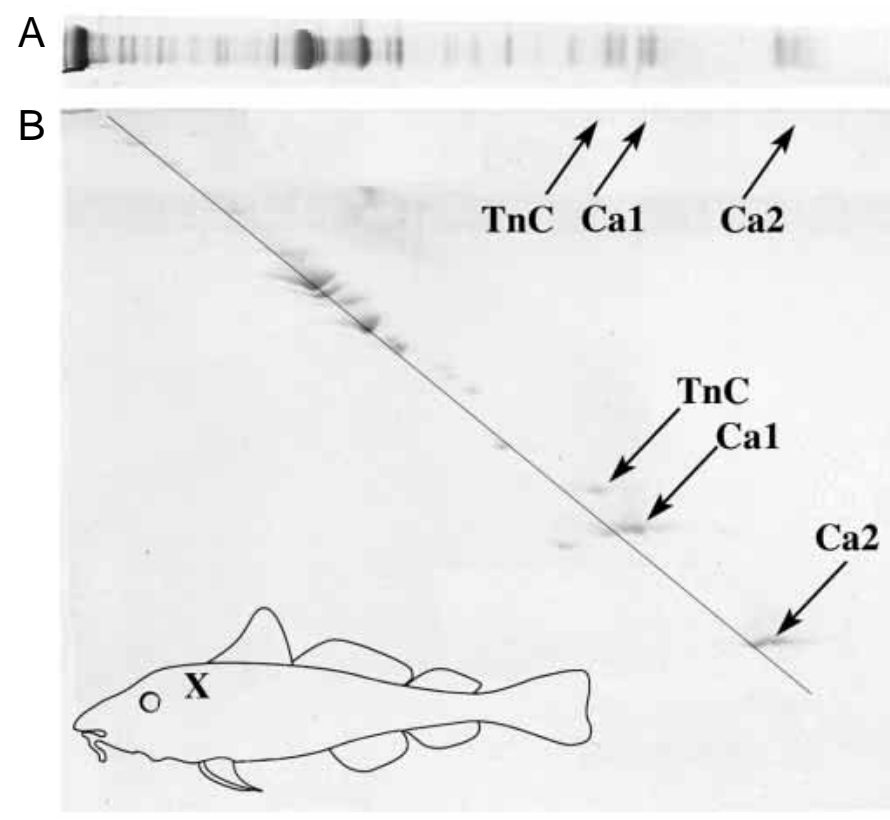

Fig. 7. Identification of two $\mathrm{Ca}^{2+}$-binding proteins by a mobility-shift assay. Two-dimensional gels, each containing $12.5 \%$ SDS polyacrylamide, electrophoresed in the presence of $1 \mathrm{mmol}^{-1}$ EDTA in the first dimension and $1 \mathrm{mmoll}^{-1} \mathrm{CaCl}_{2}$ in the second dimension, were run to identify putative $\mathrm{Ca}^{2+}$-binding proteins. A replicate of the first-dimension gel is shown in A, while $\mathrm{B}$ shows the electrophoretogram after the second dimension had been run. The sample was taken from the arm region indicated $(\mathrm{X})$ in the diagram of the fish in $\mathrm{B}$. The diagonal line represents the expected mobility boundary for proteins that are unaffected by $\mathrm{Ca}^{2+}$. Three major proteins whose mobility is shifted to the right are indicated by arrows. They correspond to troponin $\mathrm{C}(\mathrm{TnC}), \mathrm{Ca} 1$ and $\mathrm{Ca} 2$. Ca1 and $\mathrm{Ca} 2$ are cytosolic proteins that are preferentially expressed in rostral myomeres (see Fig. 4). The reduced mobility in the presence of $\mathrm{Ca}^{2+}$ (and the increase in apparent molecular mass) is typical of $\mathrm{Ca}^{2+}$ binding proteins (Burgess et al. 1980).

significant decrease in the amount of the $\mathrm{Ca}^{2+}$-binding protein parvalbumin in caudal axial muscle sites and (3) the presence of two soluble $\mathrm{Ca}^{2+}$-binding proteins in rostral muscle. Together, these factors provide compelling molecular correlates to measured differences in relaxation rates along the length of cod white axial muscle.

\section{TnT isoforms}

Although the properties of the two identified TnT isoforms have not been measured, differences in troponin $\mathrm{T}$ have been found to correlate with differences in $\mathrm{Ca}^{2+}$-sensitivity of muscle activation in numerous vertebrates, including rabbits (Schachat et al. 1987; Greaser et al. 1988; Nassar et al. 1991), chickens (Reiser et al. 1992), rats (Akella et al. 1995) and humans (Mesnard et al. 1995). Studies in which mammalian myofibrils were reconstituted with specific TnT isoforms (e.g. bovids, Tobacman and Lee, 1987; human, Wu et al. 1995) provide experimental support for a role for TnT in determining the $\mathrm{Ca}^{2+}$ concentration needed for half-maximal activation of 
the thin filament. Different combinations of TnT isoforms in rabbit axial and limb muscle have also been found to influence thin filament cooperativity, i.e. the ease with which the thin filament switches between the active and inactive states in response to the binding and release of $\mathrm{Ca}^{2+}$ (Schachat $e t$ al. 1987).

Several researchers have attempted to make simple correlations between the sensitivity and cooperativity of $\mathrm{Ca}^{2+}$ activation and the length and charge of the variable $\mathrm{N}$-terminal region that defines TnT isoforms (e.g. rabbit skeletal muscle, Greaser et al. 1988; dragonfly flight muscle, Fitzhugh and Marden, 1997). Others have found that length and charge are not the critical variables influencing muscle fiber physiology (Schachat et al. 1987; Briggs et al. 1987). Using rabbit skeletal muscle, they find that what distinguishes fibers with the lowest cooperativity is not a difference in molecular mass or in the charge structure of the muscle fiber TnT isoforms, but rather the regulated expression of TnTs that include a specific amino acid sequence encoded by mammalian exon 4. Similar specificity has been reported for chicken skeletal muscle (Reiser et al. 1992; Schachat et al. 1995) and would probably hold true for fish skeletal muscle as well.

To establish a direct molecular explanation for how TnT isoform variation affects the $\mathrm{Ca}^{2+}$ responsiveness and relaxation rates of cod axial muscle, sequence data coupled with substitution of specific TnT isoforms into myofibrils from which $\mathrm{pCa} /$ tension curves can be generated, is necessary.

\section{Parvalbumin}

In the case of parvalbumin, direct correlations between parvalbumin levels and rates of muscle relaxation have been modeled and measured experimentally (Kretsinger and Nockholds, 1973; Müntener et al. 1995). Parvalbumin has been shown to affect relaxation rates in a dose-dependent manner in both frogs (Hou et al. 1991) and mammals (Müntener et al. 1995), and it appears to affect regional relaxation rates in cod axial muscle in a similar manner. The greater the amount of parvalbumin, the faster the muscle relaxes.

Regional expression of parvalbumin, the major component of the soluble fraction of fast teleost muscle (Hamoir, 1974; Zawadowska and Supikova, 1992; Perry, 1996), has been studied by other researchers (Huriaux et al. 1996, 1997). In the adult barbel Barbus barbus, total parvalbumin concentration decreases caudally, as in cod. Huriaux et al. (1992) propose that temporal and spatial variations in total parvalbumin concentration and differential expression of parvalbumin isoforms in barbel reflect the functional requirements of the fish axial musculature according to fish size and myomeric location. To date, however, the present investigation is the first to correlate regional changes in physiology with regional differences in parvalbumin concentration.

We also performed a preliminary investigation of axial muscle proteins from a short-horned sculpin Myoxocephalus scorpius (standard length $312 \mathrm{~mm}$ ). Unlike the cod, the relaxation rate of short-horned sculpin axial muscle remains constant along the body (Johnston et al. 1993). Consistent with the effects of parvalbumin in mammals, no significant differences were detected in the parvalbumin content of rostral versus caudal white muscle samples in short-horned sculpin axial muscle.

\section{Other $\mathrm{Ca}^{2+}$-binding proteins}

The final difference detected between rostral and caudal muscle fibers is the rostral presence of two $\mathrm{Ca}^{2+}$-binding soluble proteins: $\mathrm{Ca} 1$ and $\mathrm{Ca} 2$ (Figs 4,6 ). If and how these proteins affect muscle performance is unknown. Given their relative molecular mass, a possible candidate for the highermolecular-mass protein, $\mathrm{Ca} 1$, is calmodulin, a member of the troponin $\mathrm{C}$ family, with four $\mathrm{Ca}^{2+}$-binding sites. Calmodulin plays a pivotal role in many cellular processes controlled by $\mathrm{Ca}^{2+}$ (Cheung, 1980); however, its concentration in mammalian skeletal muscle is typically so low $\left(5 \mu \mathrm{moll}^{-1}\right)$ that it cannot usually alter the cytosolic $\left[\mathrm{Ca}^{2+}\right]$ by the mere binding of $\mathrm{Ca}^{2+}$ (Gillis, 1985).

On the basis of its low relative molecular mass, a possible candidate for the $\mathrm{Ca} 2$ protein is another isoform of parvalbumin. While $\mathrm{Ca} 2$ does not react with the parvalbumin antibody, it may be parvalbumin-like and have similar effects in relaxation. Multiple parvalbumin isoforms have been reported in numerous species of fish (Gerday, 1982).

To determine the specific identity of both $\mathrm{Ca} 1$ and $\mathrm{Ca} 2$, micro-sequence data establishing amino acid sequence homologies with other known $\mathrm{Ca}^{2+}$-binding proteins would be informative.

\section{Other mechanisms controlling relaxation}

Two other mechanisms may play a part in governing rostral-caudal differences in the relaxation rate of white axial muscle in fishes. These include (1) a difference in the concentration or activity of sarcoplasmic reticulum $\mathrm{Ca}^{2+}$ ATPase (as shown to be the case in the red axial muscle of scup Stenotomus chrysops; Swank et al. 1997) and/or (2) differences in myosin (as reviewed in Gillis, 1985). Whereas neither the myosin nor the volume and surface densities of Ttubules and sarcoplasmic reticulum (Davies et al. 1995) appear to vary significantly from rostral to caudal in cod white axial muscle, it is possible that the activity of the sarcoplasmic reticulum $\mathrm{Ca}^{2+}$-ATPase may differ rostrocaudally. Experiments similar to those conducted on scup red muscle by Swank et al. (1997) could address this possibility.

Compared with the red axial muscle system of the scup, however, the white muscle system of the cod appears to regulate regional differences in relaxation rate through distinctly different mechanisms. Interestingly, while the red and white muscle systems of the scup and cod, respectively, may utilize different molecular mechanisms, the end result is similar. Both systems appear to increase the rate at which $\mathrm{Ca}^{2+}$ is removed from the myoplasm of rostral muscles. The scup appears to increase the efficiency of the sarcoplasmic reticulum $\mathrm{Ca}^{2+}$ pump in its rostral red muscle (Swank et al. 1997), while in rostral cod white muscle, increased expression of parvalbumin and differential expression of other 


\section{T. Thys, J. M. BlanK AND F. H. SCHACHAT}

myofibrillar and myoplasmic proteins appear to facilitate the rate of $\mathrm{Ca}^{2+}$ transport from the thin filament to the sarcoplasmic reticulum.

In conclusion, few studies provide direct links between molecular differences in $\mathrm{Ca}^{2+}$ regulatory proteins and their physiological function in whole muscles and whole-organism performance. This study describes a suite of rostral-caudal biochemical variations that provide compelling molecular correlates to the significantly slower relaxation rates of cod caudal axial white muscle fibers compared with rostral white muscle fibers.

Special thanks go to Dr Pokay Ma of Northeastern University's Marine Science Center at Nahant, MA, USA, and Squid's Seafood market in Chapel Hill, NC, USA, who both provided fresh cod muscle tissue. Steve Spina from the New England Aquarium provided short-horned sculpin muscle tissue. Myoseptal drawings were aided greatly by the expertise of Mark Johnston. This work was partially funded by an NIH grant EY11377 to F.H.S.

\section{References}

Akella, A. B., Ding, X. L., Cheng, R. and Gulati, J. (1995). Diminished calcium sensitivity of skinned cardiac muscle contractility coincident with troponin T-band shifts in diabetic rat. Circulation Res. 76, 600-606.

Altringham, J. D. And Johnston, I. A. (1990). Scaling effects on muscle function: power output of isolated fish muscle fibers performing oscillatory work. J. exp. Biol. 151, 453-467.

Altringham, J. D., Wardle, C. S. And Smith, C. I. (1993). Myotomal muscle function at different locations in the body of a swimming fish. J. exp. Biol. 182, 191-206.

Baylor, S. M., Chandler, W. K. and Marshall, M. W. (1983). Sarcoplasmic reticulum calcium release in frog skeletal muscle fibres estimated from Arsenazo III calcium transients. J. Physiol., Lond. 344, 625-666.

Briggs, M. M., Lin, J. J. C. AND Schachat, F. H. (1987). The extent of amino-terminal heterogeneity in rabbit fast skeletal muscle troponin T. J. Muscle Res. Cell Motil. 8, 1-12.

Burgess, W. H., Jemiolo, D. K. and Kretsinger, R. H. (1980). Interaction of calcium with calmodulin in the presence of sodium dodecyl sulfate. Biochim. biophys. Acta 623, 257-270.

Castell, C. H., SMith, B. AND Dyer, W. J. (1973). Effects of formaldehyde on salt extractable proteins of gadoid muscle. J. Fish. Res. Bd Can. 30, 1205.

Cheung, W. Y. (1980). Calmodulin plays a pivotal role in cellular regulation. Science 207, 19-27.

Connell, J. J. (1960). Studies on the proteins of fish skeletal muscle. VII. Denaturation and aggregation of cod myosin. Biochem. J. 75, 530-538.

Davies, M. L. F., Johnston, I. A. And Van de Wal, J. (1995). Muscle fibers in rostral and caudal myotomes of the Atlantic cod (Gadus morhua L.) have different mechanical properties. Physiol. Zool. 68, 673-697.

Fitzhugh, G. H. AND Marden, J. H. (1997). Maturational changes in Troponin $\mathrm{T}$ expression, $\mathrm{Ca}^{2+}$ sensitivity and twitch contraction kinetics in dragonfly flight muscle. J. exp. Biol. 200, 1473-1482.

GeKko, K. AND TimashefF, S. N. (1981). Mechanism of protein stabilization by glycerol: preferential hydration in glycerol-water mixtures. Biochemistry 20, 4667-4676.

Gerday, C. (1982). Soluble calcium-binding proteins from fish and invertebrate muscle. Molec. Physiol. 2, 63-87.

GILLIS, J. M. (1985). Relaxation of vertebrate skeletal muscle. A synthesis of the biochemical and physiological approaches. Biochim. biophys. Acta 811, 97-145.

Greaser, M. L., Moss, R. L. AND ReISER, P. J. (1988). Variation in contractile properties of rabbit single muscle fibers in relation to troponin T isoforms and myosin light chains. J. Physiol., Lond. 406, 85-98.

HAMOIR, G. (1974). Earlier and recent work on parvalbumins. Symp. biol. hung. 17, 17-33.

Hou, T. T., Johnson, J. D. AND Rall, J. A. (1991). Parvalbumin content and $\mathrm{Ca}^{2+}$ and $\mathrm{Mg}^{2+}$ dissociation rates correlated with changes in relaxation rate of frog muscle fibers. J. Physiol., Lond. 441, 285-304.

Huriaux, F., Collin, S., Vandewalle, P., Philippart, J. C. and FoCANT, B. (1997). Characterization of parvalbumin isotypes in white muscle from the barbel and expression during development. J. Fish Biol. 50, 821-836.

Huriaux, F., Melot, F., Vandewalle, P., Collin, S. and Focant, B. (1996). Parvalbumin isotypes in white muscle from three teleost fish: characterization and their expression during development. Comp. Biochem. Physiol. 113B, 475-484.

HuriauX, F., Vandewalle, P. And Focant, B. (1992). Polymorphism of white muscle myosin and parvalbumins in the genus Barbus (Teleostei: Cyprinidae). J. Fish Biol. 41, 873-882.

Johnson, T. P. And Johnston, I. A. (1991). Power output of fish muscle fibres performing oscillatory work: effect of seasonal temperature change. J. exp. Biol. 157, 409-423.

Johnson, T. P., Syme, D. A., Jayne, B. C., Lauder, G. V. AND Bennet, A. F. (1994). Modeling red muscle power output during steady and unsteady swimming in largemouth bass. Am. J. Physiol. 267, R481-R488.

Johnston, I. A., Franklin, C. E. And Johnson, T. P. (1993). Recruitment patterns and contractile properties of fast muscle fibres isolated from rostral and caudal myotomes of the short-horned sculpin. J. exp. Biol. 185, 251-265.

JosEPHSON, R. K. (1981). Temperature and the mechanical performance of insect muscle. In Insect Thermoregulation (ed. B. Heinrich), pp. 20-44. New York: Wiley.

JosEPHSON, R. K. (1985). Mechanical power output from striated muscle during cyclic contraction. J. exp. Biol. 114, 493-512.

Kelleher, S. D. AND Hultin, H. O. (1991). Lithium chloride as a preferred extractant of fish muscle proteins. J. Food Sci. 56, 315-317.

Kretsinger, R. H. And Nockolds, C. E. (1973). Carp muscle calcium-binding protein. II. Structure determination and general description. J. biol. Chem. 248, 3313-3326.

LaEmml, U. K. (1970). Cleavage of structural proteins during the assembly of the head of bacteriophage T4. Nature 227, 680-685.

LAIRD, W. M. AND MACKIE, I. M. (1981). Deterioration of frozen cod and haddock minces. In Advances in Technology in the Chilling, Freezing, Processing, Storage and Transport of Fish, Especially Underutilized Species, 395pp. International Institute of Refrigeration.

MARSH, R. L. (1990). Deactivation rate and shortening velocity as determinants of contractile frequency. Am. J. Physiol. 259, R223-R230. 
Mesnard, L., Logeart, D., Taviaux, S., Diriong, S., Mercadier, J. J. AND SAMSON, F. (1995). Human cardiac troponin T: cloning and expression of new isoforms in the normal and failing heart. Circulation Res. 76, 687-692.

Moon, T. W., Altringham, J. D. And Johnston, I. A. (1991). Energetics and power output of isolated fish fast muscle fibers performing oscillatory work. J. exp. Biol. 158, 261-273.

MüNTENER, M. L., KASER, J. AND BERChtold, M. W. (1995). Increase of skeletal muscle relaxation speed by direct injection of parvalbumin cDNA. Proc. natn. Acad. Sci. U.S.A. 92, 6504-6508.

Nassar, R., Malouf, N. N., Kelly, M. B., OAKeley, A. E. AND ANDERSON, P. A. W. (1991). Force-pCa relation and troponin $\mathrm{T}$ isoforms of rabbit myocardium. Circulation Res. 69, 1470-1475.

Neuhoff, V., Norbert, A., Taube, D. And Ehrhardt, W. (1988). Improved staining of proteins in polyacrylamide gels including isoelectric focusing gels with clear background at nanogram sensitivity using Coomassie Brilliant Blue G-250 and R-250. Electrophoresis 9, 255-262.

Perry, S. V. (1996). Molecular Mechanisms in Striated Muscle. Cambridge: Cambridge University Press.

Reiser, P. J., Greaser, M. L. AND Moss, R. L. (1992). Developmental changes in Troponin $\mathrm{T}$ isoform expression and tension production in chicken single skeletal muscle fibers. J. Physiol., Lond. 449, 573-588.

Rome, L. C. AND Swank, D. (1992). The influence of temperature on power output of scup red muscle during cyclical length changes. $J$. exp. Biol. 171, 261-281.

Rome, L. C., Swank, D. And Corda, D. (1993). How fish power swimming. Science 261, 340-343.

Rome, L. C., Syme, D. A., Hollingsworth, S., Lindstedt, S. L. AND BAYLOR, S. M. (1996). The whistle and rattle: the design of sound producing muscles. Proc. natn. Acad. Sci. U.S.A. 93, 8095-8100.

SChachat, F. H., DiAmond, M. S. ANd BRANDT, P. W. (1987). Effect of different troponin T-tropomyosin combinations on thin filament activation. J. molec. Biol. 198, 551-554.

Schachat, F., Schmidt, J. M., Maready, M. and Briggs, M. M. (1995). Chicken perinatal troponin $\mathrm{Ts}$ are generated by a combination of novel and phyolgenetically conserved alternative splicing pathways. Devl. Biol. 171, 233-239.

Swank, D. M., Zhang, G. And Rome, L. C. (1997). Contraction kinetics of red muscle in scup: mechanism for variation in relaxation rate along the length of the fish. J. exp. Biol. 200, 1297-1307.

Sweeney, H. L. AND Stull, J. T. (1990). Alteration of cross-bridge kinetics by myosin light chain phosphorylation in rabbit skeletal muscle: implications for regulation of actin-myosin interaction. Proc. natn. Acad. Sci. U.S.A. 87, 414-418.

Tobacman, L. S. AND LeE, R. (1987). Isolation and functional comparison of bovine cardiac troponin $\mathrm{T}$ isoforms. J. biol. Chem. 262, 4059-4064.

Tokunaga, T. (1964). Studies in the development of dimethylamine and formaldehyde during frozen storage. Bull. Hokk. Reg. Fish. Res. Lab. 29, 108.

Wu, Q.-L., Jha, P. K., Du, Y., Laevis, P. C. AND Sarkar, S. (1995). Overproduction and rapid purification of human fast skeletal beta troponin T using Escherichia coli expression vectors: functional differences between the alpha and beta isoforms. Gene $\mathbf{1 5 5}$, 225-230.

Zawadowska, B. AND Supikova, I. (1992). Parvalbumin in skeletal muscles of teleost (Tinca tinca L. and Misgurnus fossilis L.). Histochemical and immunohistochemical study. Folia histochem. cytobiol. 30, 63-68. 